\title{
Local Economic Structure and Growth
}

\author{
Rita Almeida* \\ World Bank Research Department
}

\begin{abstract}
This paper tests how the local economic structure - measured by local sector specialization, competition and diversity - affects the technological growth of manufacturing sectors. Most of the empirical literature on this topic assumed that in the long run more productive regions will attract more workers and use employment growth as a measure of local productivity growth. However, this approach is based on strong assumptions as that of national labor markets. In this paper I show that if we relax this assumption, regional adjusted wage growth is a better measure of regional productivity growth than employment growth. I compare the two measures using data for Portugal between 1985 and 1994. With the regional adjusted wage growth I find evidence of MAR externalities in some sectors and no evidence of Jacobs or Porter externalities in most of the manufacturing sectors. These results are at odds with my findings for employment based regressions which show that concentration and region size has a negative and significant effect in most of the manufacturing sectors. These employment based results are in line with most of the existing literature, which suggests that using employment growth to proxy for productivity growth leads to misleading results.
\end{abstract}

Keywords: Local Growth, Knowledge spillovers and Productivity. JEL Classification codes: R11, R12, O47.

\section{World Bank Policy Research Working Paper 3728, October 2005}

The Policy Research Working Paper Series disseminates the findings of work in progress to encourage the exchange of ideas about development issues. An objective of the series is to get the findings out quickly, even if the presentations are less than fully polished. The papers carry the names of the authors and should be cited accordingly. The findings, interpretations, and conclusions expressed in this paper are entirely those of the authors. They do not necessarily represent the view of the World Bank, its Executive Directors, or the countries they represent. Policy Research Working Papers are available online at http://econ.worldbank.org.

* I am very grateful to Antonio Ciccone for his guidance and to Pedro Carneiro for several comments. I thank the Economics Department at Universidade do Minho, Braga, and the Ministry of Employment for access to the data and to Ignácio Garcia, Jaume Garcia, Adriana Kugler and Rosella Nicolini for useful comments. I acknowledge the financial support of Fundação para a Ciência e Tecnologia and of the CEPR Research Training Network " Specialization versus Diversification”. Address: 1818 H Street, NW, Washington DC 20433 USA. Email: ralmeida@worldbank.org. 


\section{Introduction}

An important topic in economics is understanding the contribution of agglomeration economies and competition for local growth. Even though this is an old debate, most of the empirical work on this topic is fairly recent. Since productivity growth is not directly observed, economists have tried to find proxies for it. Most of the empirical literature used employment growth to proxy for productivity growth at the local level even though this requires strong assumptions. In this paper I examine and then relax some of these assumptions to derive an alternative measure of productivity growth based on regional wage growth. I then apply it to the study of the sources of local growth using data from a matched employer-employee data set for Portugal. With the regional adjusted wage growth I find evidence of MAR externalities in some sectors and no evidence of Jacobs or Porter externalities in most of the manufacturing sectors. These results are at odds with those for employment based regressions where concentration and region size has a negative and significant effect in most of the sectors.

The importance of scale economies in explaining the agglomeration of economic activity was first recognized by Marshall (1890). The idea behind this concept is that it would be beneficial to locate where other firms in the same sector already produce, for reasons such as the availability of intermediate goods, of specialized labor force, the existence of a large product demand or the diffusion of knowledge in the local environment. Recently, the literature on endogenous growth models emphasizes the role of dynamic information externalities as a driving force for technological innovations and, hence, for economic growth. According to this literature, the accumulation of knowledge in the geographical area, is a key driving factor for current productivity growth. Marshall (1890), Arrow (1962) and Romer (1986) argue that the most important externality derives from a buildup of knowledge associated with communications among local firms in the same sector (MAR externalities). Sector concentration in a region helps knowledge spillovers between firms and, therefore, that sector's growth in the region. This theory also predicts that local monopoly benefits growth as it restricts the flow of ideas to others and allows externalities to be internalized by the innovator. Alternative theories such as Jacobs (1969) have focused on the importance of the cross-fertilization of ideas across different sectors to promote innovation and growth (Jacobs externalities). According to this theory, more diversity in the region causes higher sector growth. Porter (1990) argues that local competition speeds up the adoption of technology. Several firms located together will intensely compete to innovate since the alternative to innovation is demise 
(Porter externalities).

Most of the empirical literature that tried to assess which type of externalities would be more favorable to local productivity growth has used employment growth to proxy for productivity growth based on the assumption that in the long-run, more productive regions would attract more workers. In general, evidence for the U.S. and Europe using employment growth as a measure of productivity growth is mixed with respect to the effect of sector concentration and diversity on regional productivity growth in manufacturing. Glaeser et al. (1992) and Peri (1992) find that local competition and urban diversity, but not regional concentration, foster employment growth in the U.S. and Italy, respectively. Combes (2000), finds evidence for France that concentration and diversity negatively affect employment growth in several sectors ${ }^{1}$. Henderson et al. (1995) find evidence of MAR externalities for the traditional capital goods industries, and of Jacobs and MAR externalities for "new" high-tech industries using data for the U.S. ${ }^{2}$.

However, using employment growth to proxy for productivity growth requires strong assumptions since employment and productivity growth need to covary positively across regions. There are several situations where this might not be the case. If there are local labor markets and labor supply shifts differently across regions (caused, for example, by labor migration), employment and productivity growth do not necessarily covary. The change in employment growth might also be smaller than increase in labor demand if there are congestion externalities such as air pollution shifting labor supply and labor demand simultaneously. Also, if the demand for output is very inelastic in some sectors, increases in productivity may translate into a small increase in labor demand since firms become able to produce more output with the same labor, and there may be reductions in the sector's employment in that region ${ }^{3}$. Furthermore, if in some sectors technological growth is labor biased, productivity growth may not translate into employment growth.

Ideally economists would like to have a direct measure for regional productivity growth. One approach is to estimate a regional production function and interpreting the residual as total productivity

\footnotetext{
${ }^{1}$ Combes (2000) finds that sector concentration fosters employment growth only in two manufacturing sectors: Glass and Office machinery and computers.

${ }^{2}$ Glaeser et al. (1992) and Henderson et al. (1995) both use data for the US and reach different conclusions. However, they analyze different time periods and the samples are constructed in different ways. In Glaeser et al. (1992) the sample includes only the six largest sectors for each city and, therefore, all sectors included have an initially high degree of concentration. Furthermore, non-manufacturing sectors such as wholesale and retail trade are heavily represented, while in Henderson et al. (1995), these are not included.

${ }^{3}$ I thank Antonio Ciccone for pointing this out.
} 
growth. However, this approach is difficult to implement because there are no consistent time series for a sufficiently long period for the stock of physical capital with a sector and a regional disaggregation. Some papers have used other measures of productivity and the evidence in these papers is more favorable to the importance of MAR externalities ${ }^{4}$. Lucio et al. (2002) study labor productivity using Spanish data and find that for regions with a high degree of sector concentration, increasing it further increases productivity growth. They find no effects of competition or diversity on labor productivity growth. Cingano and Schivardi (2002) construct a measure of productivity growth using firm level data, that is then aggregated into the region level ${ }^{5}$. They find evidence of MAR externalities for productivity growth and no effects that sector competition and diversity on local growth. These conclusions are at odds with their findings with the employment regressions, which show that sector concentration is associated with higher local growth.

In this paper I derive an alternative measure of productivity growth derived under the assumptions of local labor markets and heterogeneous workers. This measure is a wage adjusted regional growth rate, where the weights are a function of the employment growth of the different types of workers in the region. I show that this productivity measure can be derived from a model where technology is skill biased so that productivity growth and employment growth do not need to covary. Unfortunately, there are other problems related to the use of local employment growth that are also not addressed with my measure. These are the problems generated by congestition externalities arising from agglomeration economies (e.g. pollution) or from the low demand elasticity in some product markets. I use data from a matched employer-employee data set covering all the plants operating in Portugal between 1985 and 1994. This data has worker level information on total labor costs per employee supported by the plant and on the schooling and experience of the plant's workforce. I find strong evidence of MAR externalities and no effect of Porter or Jacobs externalities when pooling all the manufacturing sectors together. The results for the sector regressions show that concentration fosters employment growth in some sectors ${ }^{6}$. Sector competition and sector diversity have no effect on productivity growth in most of the manufacturing sectors ${ }^{7}$. Furthermore, my findings show that the results for productivity growth

\footnotetext{
${ }^{4}$ One exception is Gao (2003) that finds no evidence that concentration fosters industry growth in China. However, he uses output growth has a measure of productivity growth.

${ }^{5}$ They assume that the firm technology is Cobb-Douglas and estimate total factor productivity growth by obtaining an estimate for the Solow residual.

${ }^{6}$ For food, beverages and tabacco, non-metalic and mineral products and basic metals there is evidence that concentration fosters productivity growth.

${ }^{7}$ The only exceptions is chemicals, where local competition fosters productivity growth and non-metalic and mineral
} 
are at odds with those for employment growth which show that sector concentration is associated with a lower and sector competition with higher employment growth for most of the manufacturing sectors. These findings strongly suggest that using employment growth to assess the importance of the different types of externalities on productivity growth might lead to important biases.

The paper is organized as follows. Section 2.1 presents a simple theoretical model motivating the use of employment growth as a proxy for productivity growth and discusses the implications of having a local labor market. Section 2.2 extends this model to include different types of labor that are not perfect substitutes. The wage adjusted regional growth rate derived from this model is a better measure of productivity growth under the assumption of local labor markets than employment growth. Section 2.3 shows that this measure can be derived assuming that technology is labor biased, so that employment and productivity do not necessarily covary. Section 3 describes the data and section 4 describes the indices used to measure the local economic structure. The empirical results are discussed in section 5 and section 6 concludes.

\section{Models and Empirical Implementation}

As argued in the previous section, different theories argue that different local characteristics (as sector concentration, diversity or competition) are important in driving local knowledge accumulation. For example, if there are MAR externalities in a region we expect that regions that start out with more firms operating in that sector of activity, i.e., higher concentration, have higher long run productivity growth rates. Ideally economists would like to estimate for each sector the relation between these local characteristics and total local productivity growth:

$$
\widehat{A}_{r}=X_{r} \beta+\epsilon_{r}
$$

where $r$ denotes region, $\widehat{A}_{r}$ total productivity growth, $X_{r}$ is a vector of local characteristics and $\epsilon_{r}$ is an unobserved regional shock.

The approach that I take in this paper follows most of the empirical literature and assumes that the impact of the local economic structure on growth works mainly through knowledge spillovers. How-

products where local diversity fosters productivity growth. 
ever, the reduced form in equation (1) is also compatible with alternative explanations of growth. Some agglomeration forces operate directly through markets. For example Krugman (1991), Krugman and Venables(1995), Fujita and Thisse (1996) present models where natural advantages and local market conditions together with transportation costs and increasing returns to scale generate regional specialization $^{8}$.

\subsection{Local Labor Markets}

Throughout this section, and for simplicity, I assume that there is only one sector of activity. The good produced in region $r, Y_{r}$, is sold in a national market and is produced with a sector specific labor input, $L_{r}{ }^{9}$. The production function for each region ${ }^{10}$ is Cobb-Douglas and I assume decreasing returns to labor: $Y_{r}=A_{r} L_{r}^{\alpha}$, where $A_{r}$ is total factor productivity in region $r$ and $\alpha$ is constant across regions $(\alpha<1)$. Labor markets are competitive and each firm takes the real wage, $w_{r}$, as given (infinitely elastic labor supply curve ${ }^{11}$ ) The first order condition with respect to labor is given by:

$$
\alpha A_{r} L_{r}^{\alpha-1}=w_{r} \Rightarrow L_{r}=\left(\frac{\alpha A_{r}}{w_{r}}\right)^{\frac{1}{1-\alpha}}
$$

Taking growth rates,

$$
\widehat{A_{r}}=\widehat{w_{r}}+(1-\alpha) \widehat{L_{r}}
$$

A standard assumption in the literature (see e.g. Glaeser et al., 1992) is that there is a national labor market so that wage growth is constant across regions and initial wage levels differ across regions ${ }^{12}$. The latter reflects that workers might prefer to live in certain regions because there is less crime or pollution, even if wages are lower in these regions. In this case, $\widehat{w_{r}}=\widehat{w}$, and the expression in (2) can be written

as:

\footnotetext{
${ }^{8}$ Ciccone and Hall (1996) show how different models (knowledge spillovers and market based forces) can result in the same reduced form equation.

${ }^{9}$ For simplicity I assume that the stock of physical capital does not enter the production function. I relax this assumption in the next section.

${ }^{10}$ For simplicity I start from a regional level production function instead of a firm level production function. As long as the tecnhology is constant returns to scale, every firm has the same tecnhology and all the firms in the same regions face the same factor prices this procedure is valid.

${ }^{11}$ This is the assumption in most of this literature that models only the demand side of the labor market.

${ }^{12}$ The assumption of a national labor market implies that the initial wage differentials across regions increase over time in absolute terms.
} 


$$
\widehat{L_{r}}=\frac{1}{1-\alpha}\left(\widehat{A_{r}}-\widehat{w}\right)
$$

In this case, local employment growth is proportional to local productivity growth. The wage growth is constant across regions and is captured in the intercept of the reduced form equation in (1). Figure 1 illustrates this point for the case where initial wage levels are the same across regions and wage growth is positive and constant across regions $\left(\widehat{w_{r}}=\widehat{w} \neq 0\right)^{13}$. Let different regions have initially the same $A_{r}=A$ and, therefore, the same labor demand schedule, $D(A)$. Assume that all the regions face the same labor supply so that $(L, W)$ is the initial equilibrium for all the regions. Suppose that labor supply shifts from $W$ to $W^{\prime}$ in all the regions and that in some regions labor demand is higher because there is technological growth (labor demand shifts from $D(A)$ to $D^{\prime}\left(A^{\prime}\right)$ ) and in other regions labor demand is lower because there is a technological contraction (labor demand shifts from $D(A)$ to $D^{\prime \prime}\left(A^{\prime \prime}\right)$ ). This figure shows that even though there is a common shift in labor supply across regions and both regions have a reduction in employment, the $A^{\prime}$ region has a smaller employment reduction than the $A^{\prime \prime}$ region. Under these assumptions, $\widehat{A}$ and $\widehat{L}$ will be positively correlated across regions.

However, the assumption of national labor markets, in the sense that wage growth is constant across regions $\left(\widehat{w_{r}}=\widehat{w}\right)$, is strong. Figures $2 \mathrm{a}$ to $2 \mathrm{c}$ illustrate that the simple one-to-one link between $\widehat{A}$ and $\widehat{L}$ is broken if wage growth is not constant across regions. Assume the initial equilibrium is the same across regions, $(L, W)$. Let the labor supply shift differently across regions, from $W$ to $W^{\prime}$. I assume that there is technological growth in regions $I$ and $I I I$ and a technological contraction in region $I I$. The final equilibrium in regions with a technological expansion is characterized by either more employment (region $I$ ) or less employment (region $I I I$ ). In region $I I$ the technological contraction generates more employment. In this case, there is no longer a positive correlation between $\widehat{A}$ and $\widehat{L}$. One way of improving the measurement of productivity growth in the empirical work is to use the relation in equation (2), which is given directly by the model under the assumption of local labor markets. This is the approach that I take in this paper.

\footnotetext{
${ }^{13}$ The argument does not depend on the assumption that wage levels are constant across regions but it simplifies the intuition.
} 


\subsection{Heterogeneous Labor}

In this section I introduce in the previous model different types of labor. I still assume that the production function for the region-sector is Cobb-Douglas and that there are decreasing returns to two types of labor, $L_{1 r}$ and $L_{2 r}: Y_{r}=A_{r} L_{1 r}^{\alpha_{1}} L_{2 r}^{\alpha_{2}}$, with $\alpha_{1}+\alpha_{2}<0$. Aggregate labor in the region is $L_{r}=L_{1 r}+L_{2 r} . L_{1 r}$ and $L_{2 r}$ are hired at wages $w_{1 r}$ and $w_{2 r}$. This implies that the average wage in the region is given by: $w_{r}=\frac{L_{1 r}}{L_{r}} w_{1 r}+\frac{L_{2 r}}{L_{r}} w_{2 r}$. The maximization problem is given by:

$$
\operatorname{Max}_{L_{1 r} L_{2 r}} A_{r} L_{1 r}^{\alpha_{1}} L_{2 r}^{\alpha 2}-w_{1 r} L_{1 r}-w_{2 r} L_{2 r}
$$

From the first order conditions with respect to $L_{1 r}$ and $L_{2 r}$ we get that ${ }^{14}$ :

$$
\begin{aligned}
& \widehat{A_{r}}=\left(1-\alpha_{2}\right) \widehat{w_{1 r}}+\alpha_{2} \widehat{w_{2 r}}+\left(1-\alpha_{1}-\alpha_{2}\right) \widehat{L_{1 r}} \\
& \widehat{A_{r}}=\left(1-\alpha_{1}\right) \widehat{w_{2 r}}+\alpha_{1} \widehat{w_{1 r}}+\left(1-\alpha_{1}-\alpha_{2}\right) \widehat{L_{2 r}}
\end{aligned}
$$

Assuming that wage growth is constant across regions $\left(\widehat{w_{1 r}}=\widehat{w_{1}}\right.$ and $\left.\widehat{w_{2 r}}=\widehat{w_{2}}\right)$, implies that these two equations are similar to equation (2). In this case, employment growth of either $L_{1 r}$ or $L_{2 r}$ can be used to proxy for productivity growth. However, using the aggregate employment growth, instead of $\widehat{L_{1 r}}$ or $\widehat{L_{2 r}}$, would generate a different measure. Recall that $\widehat{L}_{r}=\frac{L_{1 r}}{L_{r}} \widehat{L}_{1 r}+\frac{L_{2 r}}{L_{r}} \widehat{L}_{2 r}$. Replacing the value for $\widehat{L}_{1 r}$ and $\widehat{L}_{2 r}$ from equation (5) and (6) into $\widehat{L}_{r}$ we get:

$$
\widehat{L_{r}}=\frac{1}{1-\alpha_{1}-\alpha_{2}}\left\{\widehat{A_{r}}-\widehat{w_{1 r}}\left[\left(1-\alpha_{2}\right) \frac{L_{1 r}}{L_{r}}+\alpha_{1} \frac{L_{2 r}}{L_{r}}\right]-\widehat{w_{2 r}}\left[\alpha_{2} \frac{L_{1 r}}{L_{r}}+\left(1-\alpha_{1}\right) \frac{L_{2 r}}{L_{r}}\right]\right\}
$$

\footnotetext{
${ }^{14}$ The first order conditions that are given by: $\alpha_{1} A_{r} L_{1 r}^{\alpha_{1}-1} L_{2 r}^{\alpha_{2}}=w_{1 r}$ and $\alpha_{2} A_{r} L_{1 r}^{\alpha_{1}} L_{2 r}^{\alpha_{2}-1}=w_{2 r}$. These can be solved for:

$$
\begin{aligned}
& L_{1 r}=\left[\alpha_{1}^{1-\alpha_{2}} \alpha_{2}^{\alpha_{2}} A_{r} w_{1 r}^{-\left(1-\alpha_{2}\right)} w_{2 r}^{-\alpha_{2}}\right]^{\frac{1}{1-\alpha_{1}-\alpha_{2}}} \\
& L_{2 r}=\left[\alpha_{1}^{\alpha 1} \alpha_{2}^{1-\alpha_{1}} A_{r} w_{1 r}^{-\alpha_{1}} w_{2 r}^{-\left(1-\alpha_{1}\right)}\right]^{\frac{1}{1-\alpha_{1}-\alpha_{2}}}
\end{aligned}
$$
}

So that the employment growth rates are given by:

$$
\begin{aligned}
& \widehat{L_{1 r}}=\frac{1}{1-\alpha_{1}-\alpha_{2}}\left[\widehat{A}_{r}-\left(1-\alpha_{2}\right) \widehat{w_{1 r}}-\alpha_{2} \widehat{w_{2 r}}\right] \\
& \widehat{L_{2 r}}=\frac{1}{1-\alpha_{1}-\alpha_{2}}\left[\widehat{A}_{r}-\alpha_{1} \widehat{w_{1 r}}-\left(1-\alpha_{2}\right) \widehat{w_{2 r}}\right]
\end{aligned}
$$


The usual assumption in the empirical literature is that initial wages $\left(w_{1 r}\right.$ and $\left.w_{2 r}\right)$ are different across regions but wage growth $\left(\widehat{w_{1 r}}\right.$ and $\left.\widehat{w_{2 r}}\right)$ is constant across regions. In this case, different $w_{1 r}$ and $w_{2 r}$ will imply different $\frac{L_{1 r}}{L}$ and $\frac{L_{2 r}}{L}$ across regions, and $\widehat{L_{r}}$ needs to be adjusted by a term that depends on the employment and on the regional wage growth of the different types of labor ${ }^{15}$. Therefore, if there is more than one type of labor, $\widehat{L_{r}}$ is not a good measure of proxy productivity growth. In appendix A I show that even assuming that wage levels differ across regions, aggregate employment growth might be a good proxy for productivity growth as long as we aggregate properly the different types of labor.

The intuition for the final productivity measure that I will use in the empirical work is already present in the previous models. Next I just generalize the previous model to include more realistic features as introducing capital and more than two types of labor not perfectly substitutes in the production function. In the empirical work I will group the workers into different education and potential experience ${ }^{16}$ groups creating a total of 24 categories. The production function in each region is assumed to be a general constant returns to scale in the inputs, and technology is factor neutral (Cobb-Douglas is just a particular case): $Y_{r}=A_{r} F\left(K_{r}, G_{r}\right)$, where $G_{r}=G\left(L_{1 r}, \ldots, L_{N r}\right)$ and $K_{r}$ is the total amount of physical capital and $L_{k r}$ is the number of workers of type $k$. I allow for different types of labor that are imperfectly substitutes in the production and $G($.$) is constant returns to scale in the different types of labor. I assume there$ is a total of $N$ different types of labor. The first order conditions of the maximization problem for the region are given by:

$$
\begin{gathered}
A_{r} F_{1}\left(K_{r}, G_{r}\right)=i \Rightarrow \frac{K_{r}}{G_{r}}=h(i) \\
A_{r} F_{2}\left(K_{r}, G_{r}\right)=w_{r} \Rightarrow A_{r} F_{2}\left(\frac{K_{r}}{G_{r}}, 1\right)=A_{r} F_{2}(h(i), 1)=v_{r}
\end{gathered}
$$

where $i$ is the real interest rate, $F_{1}=\frac{\partial F}{\partial K_{r}}, F_{2}=\frac{\partial F}{\partial G_{r}}$ and $v_{r}$ is the minimum cost of producing one unit of $G_{r}$, i.e., is the solution to the problem:

$$
v_{r}=\operatorname{Min}_{L_{1 r}, L_{2 r}, \ldots, L_{N r}} w_{1 r} L_{1 r}+w_{2 r} L_{2 r}+\ldots+w_{N r} L_{N r}
$$

\footnotetext{
${ }^{15}$ If $w_{1 r}=w_{1}$ and $w_{2 r}=w_{2}$, then $\frac{L_{1 r}}{L_{r}}$ and $\frac{L_{2 r}}{L_{r}}$ are equal across regions, aggregate employment growth can be used to proxy productivity growth in the empirical work.

${ }^{16}$ Age-years of schooling- 6 .
} 


$$
\text { s.t. } G\left(L_{1 r}, L_{2 r}, \ldots, L_{N r}\right) \geq 1
$$

This minimum cost function can be written as: $v_{r}=c\left(w_{1 r}, w_{2 r}, \ldots, w_{N r}\right)$, where $v_{r}($.$) is constant returns$ to scale. In the appendix B I show that the elasticities with respect to each argument equal the cost share, i.e., the wage payments to workers of type $k$ over total wage payments: $\alpha_{k r}=\frac{w_{k r} L_{k r}}{w_{r} L_{r}}$, where $L_{r}=L_{1 r}+L_{2 r}+\ldots+L_{N r}$ and $w_{r}=\sum_{k=1}^{K} w_{k r} \frac{L_{k r}}{L_{r}}$. Differentiating the minimum cost function and equation (8) yields,

$$
\begin{gathered}
\alpha_{1} \widehat{w}_{1 r}+\alpha_{2} \widehat{w}_{2 r}+\ldots+\alpha_{N} \widehat{w}_{N r}=\widehat{A}_{r}+\phi \widehat{(i)} \Leftrightarrow \\
\widehat{A}_{r}=\left[\alpha_{1} \widehat{w}_{1 r}+\alpha_{2} \widehat{w}_{2 r}+\ldots+\alpha_{N} \widehat{w}_{N r}\right]-\phi \widehat{(\hat{i})}
\end{gathered}
$$

where $\phi(\widehat{i})=\frac{\partial F_{2}(h(i), 1)}{\partial t}$. The change in total factor productivity for a given region, is equal to the changes in the wages of each type of labor weighted by the respective shares in total labor payments plus a term that is a function of the interest rate, which does not differ across regions by assumption of national market for capital. The average wage in the region is given by: $w_{r}=\sum_{k=1}^{K} w_{k r} \frac{L_{k r}}{L_{r}}$. Differentiating with respect to time:

$$
\begin{gathered}
\widehat{w}_{r}=\sum_{k=1}^{K} \widehat{w_{k r}} \frac{w_{k r} L_{k r}}{w_{r} L_{r}}+\sum_{k=1}^{K} \frac{\widehat{L_{k r}}}{L_{r}} \frac{w_{k r} L_{k r}}{w_{r} L_{r}} \Leftrightarrow \\
\widehat{w_{r}}=\sum_{k=1}^{K} \widehat{w_{k r}} \alpha_{k r}+\sum_{k=1}^{K} \frac{\widehat{L_{k r}}}{L_{r}} \alpha_{k r} .
\end{gathered}
$$

where $\alpha_{k r}=\frac{w_{k r} L_{k r}}{w_{r} L_{r}}$. Replacing this expression into equation (9a) yields,

$$
\widehat{A}_{r}=\left[\widehat{w_{r}}-\sum_{k=1}^{K} \frac{\widehat{L_{k r}}}{L_{r}} \alpha_{k r}\right]-\phi(\widehat{i}) .
$$

In the data I observe $\widehat{w_{r}}$ and $\frac{\widehat{L_{k r}}}{L_{r}}$, so that I can obtain an estimate of the $\widehat{A}_{r}$ for each region using a wage growth adjusted by employment growth. The growth in the real interest rate is constant across regions and, therefore, is captured in the intercept of the sector regressions. 


\subsection{Labor Biased Technological Change}

As argued above, one of the reasons why employment growth may be a misleading measure of productivity growth is that technology growth might be labor biased. In this case, following a positive productivity shock, there might be a reduction in total labor demand (this result is derived in appendix C). In this section I show that the expression given in equation (10), and that I will use in the empirical work, can also be derived assuming that the technology is labor biased ${ }^{17}$.

Let the production function be given by $Y_{r}=F\left(K_{r}, G\left(A_{1 r} L_{1 r}, A_{2 r} L_{2 r}, \ldots, A_{N r} L_{N r}\right)\right.$, where $F($.$) and$ $G($.$) are constant returns to scale functions, L_{r k}$ are different types of labor, and $A_{k}$ are different types of technological change. The first order conditions for capital and labor plus the assumption of constant returns to scale in $G$ and $K$ yields:

$$
\begin{gathered}
F_{1}\left(K_{r}, G_{r}\right)=i \Rightarrow \frac{K_{r}}{G_{r}}=h(i) \\
F_{2}\left(K_{r}, G_{r}\right)=w_{r} \Rightarrow F_{2}\left(\frac{K_{r}}{G_{r}}, 1\right)=F_{2}(h(i), 1)=v_{r}
\end{gathered}
$$

where $v_{r}$ is the minimum cost of producing one unit of $G_{r}$, i.e. is the solution to the problem:

$$
\begin{gathered}
v_{r}=\operatorname{Min}_{L_{1 r}, L_{2 r}, \ldots, L_{N r}} w_{r 1} L r_{1}+w_{r 2} L_{r 2}+\ldots+w_{r N} L_{r N} \\
\text { s.t. } G\left(A_{1 r} L_{1 r}, A_{2 r} L_{2 r}, \ldots, A_{N r} L_{N r}\right) \geq 1
\end{gathered}
$$

This minimum cost function can be written as: $v_{r}=c\left(\frac{w_{1 r}}{A_{1 r}}, \frac{w_{2 r}}{A_{2 r}}, \ldots, \frac{w_{N r}}{A_{N r}}\right)$ where $v_{r}($.$) has constant returns$ to scale and the elasticities with respect to each argument equal to the cost share, i.e., the wage payments to workers of type $k$ over total wage payments: $\alpha_{k r}=\frac{w_{k r} L_{k r}}{w_{r} L_{r}}$. Differentiating the minimum cost function and using equation (11) yields,

$$
\alpha_{1}\left(\widehat{w}_{1 r}-\widehat{A}_{1 r}\right)+\alpha_{2}\left(\widehat{w}_{2 r}-\widehat{A}_{2 r}\right)+\ldots+\alpha_{N}\left(\widehat{w}_{N r}-\widehat{A}_{N r}\right)=\phi(\widehat{i}) \Leftrightarrow
$$

\footnotetext{
${ }^{17}$ I thank Antonio Ciccone for pointing this out to me.
} 


$$
\alpha_{1} \widehat{A}_{1 r}+\alpha_{2} \widehat{A}_{2 r}+\ldots+\alpha_{N} \widehat{A}_{N r}=\left[\alpha_{1} \widehat{w}_{1 r}+\alpha_{2} \widehat{w}_{2 r}+\ldots+\alpha_{N} \widehat{w}_{N r}\right]-\phi \widehat{(i)}
$$

where $\phi(\widehat{i})=\frac{\partial F_{2}(h(i), 1)}{\partial t}$. Again, using the same steps has in the previous section, it can be shown that the weighted growth rates of wages within brackets in equation (13a) is equal the growth in average wages minus the growth in different types of labor weighted by their wages shares. In this case, equation (13a) can be rewritten as in equation (10):

$$
\left.\alpha_{1} \widehat{A}_{1}+\alpha_{2} \widehat{A}_{2}+\ldots+\alpha_{N} \widehat{A}_{N}=\left[\widehat{w_{r}}-\sum_{i=1}^{K} \frac{\widehat{L_{i}}}{L} \alpha_{i}\right]-\phi \widehat{i}\right)
$$

\section{Data Set and Sample Characteristics}

The data set used, "Quadros do Pessoal", is based on an annual compulsory survey conducted by the Portuguese Ministry of Labor. It is a longitudinal data file covering all the firms and plants operating in Portugal ${ }^{18}$. Records are available at worker, plant and firm level, and provide a detailed description of the labor force characteristics. At the firm and plant level, there is information for the sector of activity, regional location and the number of employees. The analysis covers the period $1985-1994^{19}$. The original data has 123, 294 and 214,047 plants and 1,8 million and 2,2 million workers in 1985 and 1994, respectively.

An important issue is the choice of the geographical unit of analysis. The location specific knowledge of a firm can be specific to the city, to the district or to another geographical unit, depending on the type of knowledge considered. The components of knowledge range from very location specific to more general ones, that cross international borders. There is evidence that knowledge spillovers are geographically localized (Jaffe et al., 1993) and most of the empirical literature has focused on metropolitan areas, based on the fact that communication is more intensive there (see Lucas, 1988). To widen the scope of the study to non-urban areas I use "concelhos" as the geographic unit ${ }^{20}$. The Portuguese Administrative Law establishes that the division of Portugal's mainland is done into 275 "concelhos", grouped together

\footnotetext{
${ }^{18}$ Except those firms without wage-earnings employees and Public Administration.

${ }^{19}$ In 1994 the classification of economic activities changed to match the European Community criteria and the correspondence between the two classifications is not unique.

${ }^{20}$ Other papers have also used different units of observations: Peri (1992) uses a data set with information at the city and province level which cover all Italian territory and Combes (2000) uses "zones d'emploi" for France, which is the most similar unit to the one used in this study.
} 
in 18 "distritos". A "concelho" is an ensemble of persons resident in a certain geographical area. It is, also, a juridical entity with its own independent administrative bodies. Their average area is 323.4 square kilometers, approximately $10 \%$ of the US county (with a standard deviation of 283.3).

All the data was aggregated from the plant level, to focus on "concelhos" and two-digit ISIC manufacturing sectors. Due to the well known problems of estimating productivity in non-manufacturing (see Griliches, 1994) in this paper I analyze only manufacturing sectors. The choice of the plant, and not the firm as the level of analysis is not arbitrary. At the firm level what matters is the regional location of the head office of a firm and, therefore, all the employment in plants outside this region is reported to the region of the head office. The average costs of labor supported by the firm and the potential experience and years of schooling of the workforce were obtained aggregating the worker level data to the plant level using the plant identifier in each worker record.

Figure 3 illustrates the evolution of unemployment rate and the cyclical component of GDP for the Portuguese economy during this period. The period 1985-1994 goes from bottom to bottom of the business cycle, and is sufficiently long to capture long term growth without being too much affected by cyclical considerations. Also these years are nearly equivalent with respect to the unemployment rate. During this period, national employment rose $16.5 \%$ and the Portuguese employment structure also registers a reasonably fast change. Figure 4 shows that the share of industrial employment is falling while agricultural employment is almost unchanged. In industry employment increases slightly $1.8 \%$, but total employment in manufacturing falls by $2.5 \%$. Figure 5 decomposes the change in the employment structure for three-digit manufacturing sectors. Wearing apparel and footwear, both with a large tradition in the Portuguese economy, were the sectors registering larger growth. They went from $9.6 \%$ and $4.1 \%$ of national manufacturing employment to $15 \%$ and $7.2 \%$, respectively. Textiles and transport equipment registered the overall worst performances in manufacturing.

These aggregate sector trends in employment growth hide the spatial disparity that each sector registered during this period. The dispersion of employment growth rates within each sector is very large. In more than $80 \%$ of the three-digit sectors, the coefficient of variation is above $100 \%$ while $53 \%$ of the sectors still have coefficients above the $200 \%$. There is also a lot of dispersion in the sector productivity growth rates across regions. The coefficients of variation within three-digit sectors are always above 100\%. On average, each "concelho" grew 53\% (standard deviation of $63 \%$ ). 


\section{Measuring the Local Economic Structure}

Since the seminal paper of Glaeser et al. (1992), the empirical literature has used employment based indeces to measure dynamic externalities ${ }^{21}$. I follow the literature and construct employment based indeces. Throughout the text the subscript $r$ stands for the geographic unit of "concelho" and $r$ for the two digit ISIC sectors. The concentration index used in this paper is the same as in Glaeser et al. (1992), i.e., the employment share of sector $s$ in region $r$.

$$
C O N_{r s}=\frac{L_{r s}}{L_{r}}
$$

where $L_{r s}$ and $L_{r}$ are the total employment in the sector-region and in the region, respectively.

Following Henderson et al. (1995) and Combes (2000), I use a measure of diversity given by the inverse of a Hirschman-Herfindhal index of sector concentration based on the employment share of other sectors on the total manufacturing employment of the region.

$$
D I V_{r s}=\frac{1}{\sum_{s^{\prime} \neq s}\left(\frac{L_{r s^{\prime}}}{L_{r}-L_{r s}}\right)^{2}}
$$

The index is maximum if the regional employment in the remaining sectors is evenly distributed. It is possible that for a given region, a sector has both a high concentration and a high diversity. This happens if there is a high concentration of employment in that sector but there are several remaining sectors all with approximately the same size.

As in Combes (2000) sector competition in region $r$ is measured by the inverse of a HirschmanHerfindhal index of productive concentration:

$$
C O M P_{r s}=\frac{1}{\sum_{i \in(r s)}\left(\frac{L_{i r s}}{L_{r s}}\right)^{2}}
$$

where $L_{i r s}$ is the employment of plant $i$ operating in sector $s$ and located in region $r$ and $L_{i s}$ is the employment of plant $i$ operating in sector $s$ and located in Portugal. Increases in the employment share of plant $i$ in total employment in region $r$ reflect less competition in the region and, therefore, a decrease

\footnotetext{
${ }^{21}$ One exception in this is Gao (2003) that uses output based indeces.
} 
in the index. This index also tends to increase with the number of plants in each sector-region.

\section{Local Economic Structure and Growth}

The model that I estimate is of the following form:

$$
\widehat{A}_{r s}=\beta^{C O N} C O N_{r s}+\beta^{D I V} D I V_{r s}+\beta^{C O M P} C O M P_{r s}+\beta^{E M P} E M P_{r}+\beta^{W} W_{r s}+\epsilon_{r s}
$$

where $C O N_{r s}, D I V_{r s}$ and $C O M P_{r s}$ are the logarithms of the indeces described in the previous section and $\epsilon_{r s}$ is an unobserved regional shock.

$\widehat{A}_{r}$ is calculated using the expression given in equation (10). For each firm I grouped workers according to their level of education and potential experience, creating a total of 24 categories $^{22}$. The average growth rates for the total cost of labor in the region-sector where then obtained by averaging this information across all the firms in the region-sector. In this expression of $\widehat{A}_{r s}$, the growth in the real interest rate is constant across regions and, therefore, is captured in the intercept of the pooled and sector regressions. I compute the productivity growth rate between 1985 and 1994 and all the indeces are computed at the beginning of the period, i.e., as of 1985. I also include as controls the initial average cost of labor in the region-sector, $W_{r s}$, to capture the fact that plants may move to low wage regions. Glaeser et al. (1992) and Henderson et al.(1995) also control for the initial sector employment in the region arguing that it might capture measurement error. However, in this context $\beta^{C O N}$ does not correctly capture the effect of the relative size of the sector because the index is reflecting differences in the total size of the regions (Combes, 1999). Following Combes (2000) I prefer a specification that controls for the initial employment in the region, $E M P_{r}$, as an explanatory variable. I also include in the regression three digit ISIC sector dummy variables to minimize the problems associated with not including other unobservable sector differences. Because the effects of the local characteristics on growth are likely to differ across sectors I present the regression results at two levels: poling all the manufacturing sectors together and within two digit ISIC sectors of activity ${ }^{23}$.

To the extent that initial conditions are predetermined, and therefore uncorrelated with the current

\footnotetext{
${ }^{22}$ In equation $(10), k=1, \ldots, 24$.

${ }^{23}$ The coeffients of interest at the three-digit sectors regressions are mostly insignificant due to the small number of observations. Instead, I run the regression at the two-digit level and include controls for three digit ISIC sectors.
} 
sector-region shocks, they can be treated as exogenous and equation (17) can be estimated with least squares. The errors are corrected for heteroskedasticity using the White correction. The final sample has approximately 2, 500 observations. Those data points with a productivity growth rate in the period considered too far from the average (more than 3 standard deviations) were excluded. Table 2 characterizes the distribution of the main variables in the sample ${ }^{24}$.

Table 2 presents the results for the sample pooling all the manufacturing sectors together. Columns (1) to (3) run the productivity growth regression entering each index at a time. Column (4) presents the results for all the indices. There is evidence of MAR externalities in columns (1) and (4), i.e., regions with a higher sector concentration tend to have higher productivity growth rates. My point estimate in column (4) implies that an increase in sector concentration that where to shift concentration from the median to the third quartile (raising sector employment 3.4 time), would be associated to an increase in local productivity by $19 \%$, i.e. approximately $2 \%$ per year between 1985 and 1994 . The effect of sector concentration is positive and statistically significant also for some sectors in table 3 as Food, Beverages and Tobacco, Nonmetallic Mineral Products and Basic Metals. There is also a positive effect of the initial region's size (measured by total employment) on productivity growth in table 2 . The point estimate in column (4) implies that doubling a region's initial size is associated with a productivity increase that is approximately $2.5 \%$ per year. The positive effect of the region's size in local productivity is present for all the manufacturing sectors in table $3^{25}$. There is no evidence that sector diversity or competition foster regional productivity growth when all the indices are included in the model, even though these variables have positive and significant effects in columns (2) and (3) of table 2. Furthermore, the sector regressions in table 3 show that this finding holds for most of the sectors. The two exceptions are Nonmetallic and Mineral products with a positive effect of sector diversity and a negative effect of sector competition on regional productivity growth and Chemicals, with a positive effect of sector competition on productivity growth. It is also a robust finding across sectors, that regions where the average labor cost is higher tend to growth less during this period in Portugal. Overall, I find robust evidence in favor of a positive effect of sector concentration on productivity growth and, therefore, evidence of MAR externalities, and no effect of sector competition and sector diversity in manufacturing sectors in Portugal during this period.

\footnotetext{
${ }^{24}$ Notice that the magnitudes of the estimated productivity growth rate presented in the table can not be directly interpreted as $\widehat{A}$ in equation (10) because it includes the term $\phi(i)$.

${ }^{25}$ It just fails to be statisticaly significant for the Textiles and Clothing sectors.
} 
One of the main criticisms to the specification (17) is the omission of variables determining productivity growth. As long as these variables are not correlated to any of the indices or variables included in the model, the omission implies that the least squares estimate is biased. Portugal entered the European Union in 1986 and, with this, several programs targeted to low income regions started to operate affecting regional productivity growth. As long as this effect is uncorrelated with total employment, already included in specification (17), this omission causes the least squares estimates to be biased. Therefore, I tested the robustness of the empirical results by including in the regression dummy variables for the 18 "distritos" and the 275 "concelhos" in Portugal. The results are reported in table 4 for the pooled sample. The effect of sector concentration on productivity growth is positive and statistically significant independently of the number of regional controls and wether or not the other indices are included. The main difference at the sector level regressions of including in the regression the region controls is that concentration has a positive and significant effect on productivity growth in the Equipment sector (results not reported). This sector category includes the manufacturing of specialized high tech sectors as electrical and optical equipment.

Tables 5 and 6 present the results of estimating the same model but using employment growth as a proxy for productivity growth. These results are interesting because they allow me to compare the previous findings with those obtained using the most common approach in the literature. The effect of sector concentration and of the region's size in table 5 are opposite for those found for productivity growth in table 3. Regions with a higher sector concentration have lower employment growth and regions with initially more employment tend to have lower employment growth rates. These findings are robust to the inclusion of sector controls at the "concelho" and "distrito" level (results not reported ${ }^{26}$ ). These results for sector concentration on employment growth are in line with what has been found by Glaeser et al. (1992) for the U.S., by Combes (2000) for France and by Cingano and Schivardi (2002) for Italy. This negative effect on growth is present for all the sectors of activity in table 6 , even though it fails to be statistically significant for two out of the eight sectors (Wood and Pulp and Paper and Publishing). There is a positive and significant effect of sector diversity on growth on column (2) of table 5 that is not robust to the inclusion of the other indices in column (4). At the sector level this effect is still not significant for all the sectors except for Chemicals where regions with a higher sector diversity have

\footnotetext{
${ }^{26}$ The coefficient of sector concentration ranges from - 0.21 (0.01) with 275 "concelhos" and no other indeces are included to $-0.23(0.01)$ with 18 "distritos" and the competition and diversity indeces included.
} 
lower employment growth ${ }^{27}$. The effect of sector competition on employment growth is positive and statistically significant in table 5 for the pooled sample. This positive effect of sector competition is present for all the manufacturing sectors except for Nonmetallic Mineral Products, Basic Metals and Equipment.

In sum, the results obtained with employment and with productivity growth are very different. With employment growth there is no evidence of MAR externalities and there is a positive effect of sector competition on local employment growth. Using a wage adjusted measure of productivity growth, which is derived under less restrictive assumptions than the employment growth measure of productivity, I find evidence of a significant effect of sector concentration on growth. Moreover, there is evidence for most of the manufacturing sectors that regions that are initially larger tend to grow faster. This disparity in the empirical findings obtained with employment and productivity based regressions, and the importance of MAR externalities for local growth are also in line with other papers that recently have tried to find better measures of local productivity growth (see e.g. Cingano and Schivardi, 2002). I interpret these findings to mean that the empirical literature using employment growth suffers from serious identification problems to disentangle the sources knowledge spillovers in local growth.

\section{Conclusion}

This paper assumes that local characteristics affect the accumulation of location specific knowledge and, therefore, of local technological growth. I test how the local economic structure, measured by local sector specialization, competition and diversity, affect the technological growth of Portuguese regions between 1985 and 1994. The previous literature on this topic assumed that in the long run more productive regions will attract more workers and, therefore, the growth rate of employment was used as a measure of local productivity growth. However, productivity growth will translate into a proportional employment growth only under strong assumptions. In particular these two variables will be positively correlated assuming that there is a national labor market. In this paper I relax this assumption and allow for different types of labor to derive an alternative measure of productivity growth based on the local wage growth adjusted by the employment growth of the different types of labor. My empirical findings support the existence of MAR externalities in Portuguese regions between 1985 and 1994 for some manufacturing sectors and

\footnotetext{
${ }^{27}$ The sign of diversity on growth is negative for employment and produtcivity growth.
} 
no effect of sector competition and sector diversity for most of the sectors. Moreover, the results are at odds with those found with the employment based regressions where, as in most of this literature, there is evidence that sector concentration has a negative effect and sector competition a positive effect on local employment growth. I interpret these findings to mean that using employment growth to proxy for productivity growth leads to misleading results. 


\section{References}

[1] Ciccone, A., Hall, R. (1996) Productivity and the Density of Economic Activity, American Economic Review, 86: 54-70.

[2] Cingano, F. and Schivardi, F. (2002) Identifying the Sources of Local Productivity Growth. mimeo. Bank of Italy.

[3] Combes, P. (1999) Marshall-Arrow-Romer externalities and city growth: A methodological note. Working Paper 99-06, CERAS.

[4] Combes P. (2000) Economic Structure and Local Growth: France 1984-1993, Journal of Urban Economics, 47: 329-355.

[5] De Lucio, J., Herce, J. and Goicolea, A. (2002) The Effects of Externalities on Productivity Growth in Spanish Industry, Regional Science and Urban Economics, 32: 241-258.

[6] Fujita, M. and Thisse, J. (1996) Economics of agglomeration, Journal of the Japanese and International Economies, 10: 339-378.

[7] Gao, T. (2003) Regional industrial growth: evidence from Chinese industries, Regional Science and Urban Economics, forthcoming.

[8] Glaeser, E., Kallal H.,Sheikman, J. and Shleifer, A. (1992) Growth in cities, Journal of Political Economy, 100: 1126-1152.

[9] Griliches, Zvi. (1994) Productivity, R\&D, and the Data Constraint, American Economic Review: $84,1-23$.

[10] Henderson, J., Kuncoro A. and Matthew M. (1995) Industrial Development in cities, Journal of Political Economy, 103: 1067-1090.

[11] Jaffe, A., Trajtenberg, M., Henderson, R. (1993) Geographic localization of knowledge spillovers as evidenced by patent citations. Quarterly Journal of Economics, 108: 577-598.

[12] Lucas, R. (1988) On the mechanics of economic development, Journal Monetary Economics, 22: $3-42$.

[13] Marshall, A. (1890) Principles of economics. London: Macmillan.

[14] Krugman, P. (1991) Increasing returns and economic geography, Journal of Political Economy, 99: 483-499.

[15] Krugman, P. and Venables A. (1995) Globalization and the inequality of nations, Quaterly Journal of Economics, 110: 857-880.

[16] Peri, G. (1992) Local characteristics and growth in Italian cities and provinces: 1961-1991, mimeo University of California, Berkeley.

[17] Porter, P. (1990) The competitive advantage of nations. New York: Free Press.

[18] Banco de Portugal, Relatório e contas, 1985-1994 


\section{Appendix}

\section{A.1 Computing an Aggregate Employment Growth with Heterogeneous Labor}

In this section I show that aggregate employment growth might be a good proxy for productivity growth as long as we aggregate properly the different types of labor. Let $Y_{r}=A_{r} L_{r}^{\prime} \alpha_{1}+\alpha_{2}$, where $\alpha_{1}+\alpha_{2}<0$ and $L_{r}^{\prime}=L_{1 r}^{\frac{\alpha_{1}}{\alpha_{1}+\alpha 2}} L_{2 r}^{\frac{\alpha_{2}}{\alpha_{1}+\alpha 2}}$ is constant returns to scale in $L_{1 r}$ and $L_{2 r}$. Let $v_{r}^{\prime}$ be the minimal cost of one unit of $L_{r}^{\prime}$ so that:

$$
\begin{gathered}
\operatorname{Min}_{L_{1 r}, L_{2 r}} w_{1 r} L_{1 r}+w_{2 r} L_{2 r} \\
\text { s.t. } L_{1 r}^{\frac{\alpha_{1}}{\alpha_{1}+\alpha^{2}}} L_{2 r}^{\frac{\alpha_{2}}{\alpha_{1}+\alpha^{2}}} \geq 1
\end{gathered}
$$

In appendix A.2 I show that the solution to this problem implies that:

$$
v_{r}^{\prime}=\left[\frac{\alpha_{1} w_{2 r}}{\alpha_{2} w_{1 r}}\right]^{\frac{\alpha_{2}}{\alpha_{1}+\alpha_{2}}} w_{1 r}+\left[\frac{\alpha_{2} w_{1 r}}{\alpha_{1} w_{2 r}}\right]^{\frac{\alpha_{1}}{\alpha_{1}+\alpha_{2}}} w_{2 r}
$$

Therefore, the initial problem given in (4) can be rewritten as the following problem using just one aggregate type of labor:

$$
\operatorname{Max}_{L_{r}^{\prime}} A_{r} L_{r}^{\alpha_{1}+\alpha_{2}}-w_{r}^{\prime} L_{r}^{\prime}
$$

Assuming a national labor market for both types of labor, $\widehat{w_{1 r}}=\widehat{w_{1}}$ and $\widehat{w_{2 r}}=\widehat{w_{2}}$ would imply that $\widehat{w}_{r} \neq \widehat{w}$ but ${\widehat{w^{\prime}}}_{r}={\widehat{w^{\prime}}}^{\prime}$. Then we can use aggregate employment growth to proxy productivity growth as long as we use $L_{r}^{\prime}$ as the measure of aggregate employment. In this case, the equivalent to equation (3) is given by $\widehat{L_{r}^{\prime}}=\frac{1}{1-\alpha_{1}-\alpha_{2}} \widehat{A_{r}}+\widehat{w_{r}^{\prime}}$. If aggregate wage growth is constant across regions then it is captured by the intercept of the sector regression. With local labor markets, it is sufficient to construct the correct aggregate wage, $w_{r}^{\prime}$, given by equation (18) in the text. The equivalent to equation (2) in the text is now:

$$
\widehat{A_{r}}=\widehat{w_{r}^{\prime}}+\left(1-\alpha_{1}-\alpha_{2}\right) \widehat{L_{r}^{\prime}} .
$$

\section{A.2 Deriving the Minimum Cost Function}

Let $v_{r}^{\prime}$ be the minimum cost of one unit of $L_{r}^{\prime}$ so that it is the solution to the following problem:

$$
\begin{gathered}
\operatorname{Min}_{L_{1 r}, L_{2 r}} w_{1 r} L_{1 r}+w_{2 r} L_{2 r} \\
\text { s.t. } L_{1 r}^{\frac{\alpha_{1}}{\alpha_{1}+\alpha_{2}}} L_{2 r}^{\frac{\alpha_{2}}{\alpha_{1}+\alpha_{2}}} \geq 1
\end{gathered}
$$

This minimum cost function can be written as: $v_{r}=c\left(w_{1 r}, w_{2 r}, \ldots, w_{N r}\right)$. The Lagrangian of this problem is:

$$
L=w_{1 r} L_{1 r}+w_{2 r} L_{2 r}+\mu\left(1-L_{1 r}^{\frac{\alpha_{1}}{\alpha_{1}+\alpha_{2}}} L_{2 r}^{\frac{\alpha_{2}}{\alpha_{1}+\alpha_{2}}}\right)
$$

The first order conditions: 


$$
\begin{gathered}
\frac{\partial L}{\partial L_{1 r}}=w_{1 r}-\mu\left(\frac{\alpha_{1}}{\alpha_{1}+\alpha_{2}} L_{1 r}^{\frac{-\alpha_{2}}{\alpha_{1}+\alpha_{2}}} L_{2 r}^{\frac{\alpha_{2}}{\alpha_{1}+\alpha_{2}}}\right)=0 \\
\frac{\partial L}{\partial L_{2 r}}=w_{2 r}-\mu\left(\frac{\alpha_{1}}{\alpha_{1}+\alpha_{2}} L_{1 r}^{\frac{\alpha 1}{\alpha_{1}+\alpha_{2}}} L_{2 r}^{\frac{-\alpha 1}{\alpha_{1}+\alpha_{2}}}\right)=0 \\
\frac{\partial L}{\partial \mu}=1-L_{1 r}^{\frac{\alpha_{1}}{\alpha_{1}+\alpha_{2}}} L_{2 r}^{\frac{\alpha_{2}}{\alpha_{1}+\alpha_{2}}}=0
\end{gathered}
$$

Dividing the first two conditions: $\frac{L_{1 r}}{L_{2 r}}=\frac{\alpha_{2} w_{2 r}}{\alpha_{1} w_{1 r}}$ and replacing into:

$$
{\frac{L_{1 r}}{L_{2 r}}}^{\frac{\alpha_{1}}{\alpha_{1}+\alpha 2}} L_{2 r}=1 \text { and }{\frac{L_{2 r}}{L_{1 r}}}^{\frac{\alpha_{2}}{\alpha_{1}+\alpha 2}} L_{1 r}=1
$$

yields:

$$
\begin{aligned}
& L_{1 r}=\frac{\alpha_{2} w_{2 r}}{\alpha_{1} w_{1 r}}\left(\frac{\alpha_{1}}{\alpha_{1}+\alpha_{2}}\right) \\
& L_{2 r}=\frac{\alpha_{1} w_{1 r}}{\alpha_{2} w_{2 r}}\left(\frac{\alpha_{2}}{\alpha_{1}+\alpha_{2}}\right)
\end{aligned}
$$

Replacing into the definition of minimum cost function: $v_{r}^{\prime}=w_{1 r} L_{1 r}+w_{2 r} L_{2 r}$ gives:

$$
v_{r}^{\prime}=\left[\frac{\alpha_{1} w_{2 r}}{\alpha_{2} w_{1 r}}\right]^{\frac{\alpha_{2}}{\alpha_{1}+\alpha_{2}}} w_{1 r}+\left[\frac{\alpha_{2} w_{1 r}}{\alpha_{1} w_{2 r}}\right]^{\frac{\alpha_{1}}{\alpha_{1}+\alpha_{2}}} w_{2 r}
$$




\section{B. The Minimum Cost Function}

Let $w_{r}$ be the the minimum cost of producing one unit of $G_{r}$, i.e. is the solution to the problem:

$$
\begin{gathered}
\operatorname{Min}_{L_{1 r}, \ldots L_{N r}} w_{1 r} L_{1 r}+w_{2 r} L_{2 r}+\ldots+w_{N r} L_{N r} \\
\text { s.t. } G\left(L_{1 r}, L_{2 r}, \ldots, L_{N r}\right) \geq 1
\end{gathered}
$$

The Lagrangian of this problem is:

$$
L=w_{1 r} L_{1 r}+w_{2 r} L_{2 r}+\ldots+w_{N r} L_{N r}+\mu\left(1-G\left(L_{1 r}, L_{2 r}, \ldots, L_{N r}\right)\right)
$$

The first order conditions can be solved to get:

$$
\begin{gathered}
w_{k r}=\mu \frac{\partial G(.)}{\partial L_{k r}}, k=1 \ldots N \\
w_{k r} L_{k r}=\mu \frac{\partial G(.)}{\partial L_{k r}} L_{k r} .
\end{gathered}
$$

Taking sums for all the types of labor:

$$
\sum_{k=1}^{K} w_{k r} L_{k r}=\mu \sum_{k=1}^{K} \frac{\partial G(.)}{\partial L_{k r}} L_{k r}
$$

Because $G($.$) is constant returns to scale, it is homogeneous of degree 1$ so that $G=\sum_{k=1}^{K} \frac{\partial G(.)}{\partial L_{k r}} L_{k r}$. Then the expression above becomes $\sum_{k=1}^{K} w_{k r} L_{k r}=\mu G($.$) . On the other hand w_{r}$ is the minimum cost of "producing" one unit of $G($.$) so that \sum_{k=1}^{K} w_{k r} L_{k r}=w_{r} G($.$) . From these two equations it must be that$ $\mu=w_{r}$. Then, from the first order condition:

$$
w_{k r}=w_{r} \frac{\partial G(.)}{\partial L_{k r}}
$$

Multiplying both sides by $\frac{L_{k r}}{G(.)}$ and rearranging the terms we get:

$$
\frac{\partial G(.)}{\partial L_{k r}} \frac{L_{k r}}{G(.)}=\frac{w_{k r} L_{k r}}{G(.) w_{r}} .
$$

Therefore, the elasticities of $G($.$) with respect to each argument equal to the cost share, i.e., the wage$ payments to workers of type $k$ over total wage payments: $\alpha_{k r}=\frac{w_{k r} L_{k r}}{w_{r} L_{r}}$. 


\section{Implications of Factor Neutral and Labor Biased Technical Change for Employment Growth}

Suppose the production function for each region is constant returns to scale and technological progress is factor neutral:

$$
Y=A F(K, L)
$$

Then the first order conditions for the region's problem are:

$$
\begin{aligned}
& A \frac{\partial F}{\partial K}=i \\
& A \frac{\partial F}{\partial L}=w
\end{aligned}
$$

Totally differentiating this system we obtain:

$$
\begin{aligned}
& A \frac{\partial^{2} F}{\partial K^{2}} d K+A \frac{\partial^{2} F}{\partial K \partial L} d L+\frac{\partial F}{\partial K} d A=0 \\
& A \frac{\partial^{2} F}{\partial L \partial K} d K+A \frac{\partial^{2} F}{\partial L^{2}} d L+\frac{\partial F}{\partial L} d A=0
\end{aligned}
$$

Then

$$
\frac{d L}{d A}=\frac{-\frac{\partial F}{\partial L}+A \frac{\frac{\partial^{2} F}{\partial L \partial K} \frac{\partial F}{\partial K}}{A \frac{\partial^{2} F}{\partial K^{2}}}}{A\left[-\frac{\left(\frac{\partial^{2} F}{\partial L \partial K}\right)^{2}}{\frac{\partial^{2} F}{\partial K^{2}}}+\frac{\partial^{2} F}{\partial L^{2}}\right]}
$$

If $F$ is increasing and concave in $K$ and $L$ then the first term in the numerator is negative and so is the second if $\frac{\partial^{2} F}{\partial L \partial K}>0$ ( $K$ and $L$ are complementary). If second order condition of the maximization problem hold we know that $\frac{\partial^{2} F}{\partial K^{2}}<0, \frac{\partial^{2} F}{\partial L^{2}}<0$ and $\frac{\partial^{2} F}{\partial K^{2}} \frac{\partial^{2} F}{\partial L^{2}}-\frac{\partial^{2} F}{\partial L \partial K}>0$. Therefore, the denominator is negative.

If $F($.$) is constant returns to scale, i.e., F($.$) is homogeneous of degree 1$ and the Euler Theorem applies :

$$
\frac{\partial F}{\partial L} L+\frac{\partial F}{\partial K} K=F
$$

and

$$
\frac{\partial^{2} F}{\partial L^{2}} L+\frac{\partial^{2} F}{\partial L \partial K} K=0
$$

which implies that

$$
\frac{\partial^{2} F}{\partial L \partial K}=-\frac{\partial^{2} F}{\partial L^{2}} \frac{L}{K}>0
$$

Therefore, if $F($.$) is homogeneous of degree 1$ and $K$ and $L$ are complements in the production function we get that $\frac{d L}{d A}>0$. In other words, with factor neutral technological progress increases in $A$ translate into increases in $L$ holding prices constant.

Assume now that technical change is labor biased:

$$
Y=F(K, G)
$$


where $G=A L$ and $F$ is homogeneous of degree 1 . Then the first order conditions for the region's problem are:

$$
\begin{aligned}
\frac{\partial F}{\partial K} & =i \\
A \frac{\partial F}{\partial L} & =w
\end{aligned}
$$

Totally differentiating this system we obtain:

$$
\begin{aligned}
\frac{\partial^{2} F}{\partial K^{2}} d K+\frac{\partial^{2} F}{\partial K \partial G}[A d L+L d A] & =0 \\
A \frac{\partial^{2} F}{\partial G \partial K} d K+A \frac{\partial^{2} F}{\partial G^{2}}[A d L+L d A]+\frac{\partial F}{\partial G} d A & =0
\end{aligned}
$$

'Then

$$
\frac{d K}{d A}=-\frac{\frac{\partial^{2} F}{\partial K \partial G}}{\frac{\partial^{2} F}{\partial K^{2}}}\left[A \frac{d L}{d A}+L\right]
$$

Solving this expression for $\frac{d L}{d A}$ yields:

$$
\frac{d L}{d A}=\frac{-\frac{\frac{\partial F}{\partial G}}{A\left[-\frac{\left(\frac{\partial^{2} F}{\partial G K}\right)^{2}}{\frac{\partial^{2} F}{\partial K^{2}}}+\frac{\partial^{2} F}{\partial G^{2}}\right]}-L}{A} \gtrless 0
$$

Again, the term within brackets will be negative so that $A \frac{d L}{d A}+L>0$. But $\frac{d L}{d A}=\frac{\varphi-L}{A} \gtrless 0$, where $\varphi=-\frac{\frac{\partial F}{\partial G}}{A\left[-\frac{\left(\frac{\partial^{2} F}{\partial G K}\right)^{2}}{\frac{\partial^{2} F}{\partial K^{2}}}+\frac{\partial^{2} F}{\partial G^{2}}\right]}$. Therefore, if technical change is labor biased then $L$ can increase or decrease when $A$ increases. 


\section{Sector Disaggregation by two digit ISIC sectors}

Sector Name

Food, Beverages and Tobacco

Textiles and Clothing

Wood and Pulp

Paper and Publishing

Chemicals

Non-Metallic Mineral Products

Basic Metals

Equipment
Sector Composition

Food, Beverages, Tobacco

Textiles, Clothing, Leather Products

Wood, Pulp (cork), Furniture

Paper, Publishing

Chemicals, Oil and Coal Derivatives, Rubber, Plastic

Porcelain, Clay, Glass

Steal, Iron

Machinery, Electronics, High-Precision Instruments,

Transports and Transport Material 
Table 1: Descriptive Statistics

\begin{tabular}{lccccc}
\hline \hline & Mean & Std Deviation & P25 & P50 & P75 \\
\hline Employment Growth & & & & & \\
Concentration & 0.17 & 0.91 & -0.34 & 0.14 & 0.69 \\
Competition & 0.10 & 0.16 & 0.01 & 0.03 & 0.10 \\
Diversity & 28.2 & 44.0 & 6.5 & 15.1 & 33.4 \\
Average cost of labor & 4.8 & 2.9 & 2.6 & 4.1 & 6.1 \\
Employment in the region & 7.18 & 0.36 & 7.01 & 7.17 & 7.37 \\
Estimated Productivity Growth & 6,974 & 10,986 & 566 & 2,313 & 9,943 \\
& 2.9 & 2.0 & 2.1 & 2.6 & 3.2 \\
\hline
\end{tabular}

Source: "Quadros de Pessoal"

Notes: All the variables except Employment in the region, are averages for the region-sector, where region stands for "concelho" and sector for the two-digit ISIC sectors. Growth rates are computed between 1985 and 1994 and the other variables are for 1985. All the statistics are computed excluding the region-sectors with employment growth rates smaller than 3 standard deviations from the average. Concentration is the employment's share in the total employment of the region,

Competition is the Hirschman-Herfindhal index, Diversity is the Hirschman-Herfindhal index for diversity, Average cost of labor is the log of average labor costs per employee (in Euros), Employment in the region is the total number of employees in the region and Estimated Productivity Growth is the estimated productivity using the formula derived in Section 2.3 . 
Table 2: Dynamic Externalities and the Long-Run

Productivity Growth in Manufacturing

\begin{tabular}{|c|c|c|c|c|}
\hline \multicolumn{5}{|c|}{ Dependent Variable: Productivity growth 1985 - 1994 in the "concelho"-sector } \\
\hline Specification & (1) & (2) & (3) & (4) \\
\hline \multirow[t]{2}{*}{ Concentration } & 0.0653 & & & 0.0576 \\
\hline & {$[0.018229]^{* * *}$} & & & {$[0.019290]^{* * *}$} \\
\hline \multirow[t]{2}{*}{ Diversity } & & 0.0839 & & 0.0604 \\
\hline & & {$[0.043661]^{*}$} & & [0.043798] \\
\hline \multirow[t]{2}{*}{ Competition } & & & 0.0502 & 0.0284 \\
\hline & & & {$[0.025617]^{*}$} & [0.026982] \\
\hline \multirow[t]{2}{*}{ Wage } & -2.3382 & -2.2055 & -2.1709 & -2.3190 \\
\hline & {$[0.128652]^{* * *}$} & {$[0.122479]^{* * *}$} & {$[0.121653]^{* * *}$} & {$[0.132892]^{* * *}$} \\
\hline \multirow[t]{2}{*}{ Employment } & 0.1544 & 0.1156 & 0.1138 & 0.1358 \\
\hline & {$[0.014342]^{* * *}$} & {$[0.014702]^{* * *}$} & {$[0.015190]^{* * *}$} & {$[0.018484]^{* * *}$} \\
\hline Region Controls & $\mathrm{N}$ & $\mathrm{N}$ & $\mathrm{N}$ & $\mathrm{N}$ \\
\hline Observations & 2,382 & 2,380 & 2,379 & 2,382 \\
\hline Adjusted R-squared & 0.30 & 0.29 & 0.29 & 0.30 \\
\hline
\end{tabular}

Note: Standard errors in parenthesis. $* * *$ significant at $99 \%$; $* *$ significant at $95 \%$; significant at $90 \%$. Concentration is the log of the sector's employment share in the region, Diversity is the log of the Hirschman. Herfindhal index, Competition is the log of the Hirschman-Herfindhal index of competition, Wages are the $\log$ of total labor costs per month per employee in the region-sector (Euros) and Employment the log of the total local employment in the region. Sector dummies are included at a 3-digit ISIC sector level. 
Table 3: Estimates of the Long Run Productivity Growth Model, by two-digit ISIC sectors

\begin{tabular}{|c|c|c|c|c|c|c|c|c|}
\hline \multicolumn{9}{|c|}{ Dependent Variable: Productivity Growth 1985 - 1994 in the "concelho"-sector } \\
\hline Sector & $\begin{array}{c}\text { Food, Beverages } \\
\text { and Tabacco } \\
\end{array}$ & $\begin{array}{c}\text { Textiles } \\
\text { and Clothing }\end{array}$ & $\begin{array}{c}\text { Wood } \\
\text { and Pulp }\end{array}$ & $\begin{array}{c}\text { Paper } \\
\text { and Publishing } \\
\end{array}$ & Chemicals & $\begin{array}{l}\text { Non-Metalic } \\
\text { Mineral Prod. }\end{array}$ & $\begin{array}{r}\text { Basic Metals } \\
\text { (Steal, Iron) } \\
\end{array}$ & Equipment \\
\hline Concentration & $\begin{array}{c}0.185 \\
{[0.0486]^{* * *}}\end{array}$ & $\begin{array}{c}-0.007 \\
{[0.0430]}\end{array}$ & $\begin{array}{c}0.040 \\
{[0.0422]}\end{array}$ & $\begin{array}{c}0.112 \\
{[0.0849]}\end{array}$ & $\begin{array}{c}0.027 \\
{[0.0714]}\end{array}$ & $\begin{array}{c}0.088 \\
{[0.0533]}\end{array}$ & $\begin{array}{c}0.263 \\
{[0.1219]^{* *}}\end{array}$ & $\begin{array}{c}0.083 \\
{[0.0480]^{*}}\end{array}$ \\
\hline Diversity & $\begin{array}{c}0.045 \\
{[0.1057]}\end{array}$ & $\begin{array}{c}0.107 \\
{[0.0992]}\end{array}$ & $\begin{array}{c}-0.056 \\
{[0.1041]}\end{array}$ & $\begin{array}{c}-0.079 \\
{[0.1528]}\end{array}$ & $\begin{array}{c}-0.037 \\
{[0.2169]}\end{array}$ & $\begin{array}{c}0.114 \\
{[0.1597]}\end{array}$ & $\begin{array}{c}-0.069 \\
{[0.2660]}\end{array}$ & $\begin{array}{c}-0.057 \\
{[0.1020]}\end{array}$ \\
\hline Competition & $\begin{array}{c}-0.157 \\
{[0.1761]}\end{array}$ & $\begin{array}{c}-0.032 \\
{[0.0985]}\end{array}$ & $\begin{array}{c}-0.085 \\
{[0.0697]}\end{array}$ & $\begin{array}{c}0.025 \\
{[0.2828]}\end{array}$ & $\begin{array}{c}0.060 \\
{[0.1521]}\end{array}$ & $\begin{array}{c}-0.287 \\
{[0.1685]^{*}}\end{array}$ & $\begin{array}{c}-0.318 \\
{[0.3030]}\end{array}$ & $\begin{array}{c}0.053 \\
{[0.1133]}\end{array}$ \\
\hline Wage & $\begin{array}{c}-2.237 \\
{[0.2342]^{* * *}}\end{array}$ & $\begin{array}{c}-2.701 \\
{[0.3952]^{* * *}}\end{array}$ & $\begin{array}{c}-2.413 \\
{[0.2942]^{* * *}}\end{array}$ & $\begin{array}{c}-2.207 \\
{[0.4172]^{* * *}}\end{array}$ & $\begin{array}{c}-1.630 \\
{[0.4842]^{* * *}}\end{array}$ & $\begin{array}{c}-2.819 \\
{[0.3087]^{* * *}}\end{array}$ & $\begin{array}{c}-2.293 \\
{[0.4439]^{* * *}}\end{array}$ & $\begin{array}{c}-3.214 \\
{[0.2936]^{* * *}}\end{array}$ \\
\hline Employment & $\begin{array}{c}0.164 \\
{[0.0400]^{* * *}}\end{array}$ & $\begin{array}{c}0.085 \\
{[0.0508]^{*}}\end{array}$ & $\begin{array}{c}0.110 \\
{[0.0416]^{* * *}}\end{array}$ & $\begin{array}{c}0.166 \\
{[0.0624]^{* * *}}\end{array}$ & $\begin{array}{c}0.130 \\
{[0.1124]}\end{array}$ & $\begin{array}{c}0.222 \\
{[0.0656]^{* * *}}\end{array}$ & $\begin{array}{c}0.270 \\
{[0.1505]^{*}}\end{array}$ & $\begin{array}{c}0.218 \\
{[0.0488]^{* * *}}\end{array}$ \\
\hline $\begin{array}{l}\text { Observations } \\
\text { Adjusted R-squared }\end{array}$ & $\begin{array}{c}388 \\
0.3\end{array}$ & $\begin{array}{l}298 \\
0.45\end{array}$ & $\begin{array}{l}354 \\
0.34\end{array}$ & $\begin{array}{c}195 \\
0.33\end{array}$ & $\begin{array}{l}255 \\
0.26\end{array}$ & $\begin{array}{l}272 \\
0.42\end{array}$ & $\begin{array}{c}66 \\
0.41\end{array}$ & $\begin{array}{l}490 \\
0.41\end{array}$ \\
\hline
\end{tabular}

Note : Standard errors in parenthesis. *** significant at 99\%; ** significant at $95 \%$; significant at $90 \%$. Concentration is the log of the sector's employment share in the region, Diversity is the log of the Hirschman-Herfindhal index, Competition is the log of the Hirschman-Herfindhal index of competition, Wages are the log of total labor costs per month per employee in the region-sector (Euros) and Employment the log of the total local employment in the region. Sector dummies are included at a 3-digit ISIC sector level. 
Table 4: Dynamic Externalities and the Long-Run

Productivity Growth in Manufacturing (Region Controls included)

\begin{tabular}{|c|c|c|c|c|}
\hline \multicolumn{5}{|c|}{ Dependent Variable: Productivity growth 1985 - 1994 in the "concelho"-sector } \\
\hline Specification & (1) & (2) & (3) & (4) \\
\hline \multirow[t]{2}{*}{ Concentration } & 0.0824 & 0.0798 & 0.0761 & 0.0780 \\
\hline & {$[0.017619]^{* * *}$} & {$[0.018109]^{* * *}$} & {$[0.018251]^{* * *}$} & {$[0.019106]^{* * *}$} \\
\hline \multirow[t]{2}{*}{ Diversity } & & 0.0999 & & -0.033506 \\
\hline & & [0.142982] & & [0.046671] \\
\hline \multirow[t]{2}{*}{ Competition } & & 0.0136 & & -0.001902 \\
\hline & & [0.036343] & & [0.035824] \\
\hline \multirow[t]{2}{*}{ Wage } & -2.6062 & -2.5921 & -2.50268 & -2.496905 \\
\hline & {$[0.095691]^{* * *}$} & {$[0.096241]^{* * *}$} & {$[0.137602] * * *$} & {$[0.138509]^{* * *}$} \\
\hline \multirow{2}{*}{ Employment } & & & 0.139379 & 0.143746 \\
\hline & & & {$[0.019108]^{* * *}$} & {$[0.020491]^{* * *}$} \\
\hline Region Controls & 275 & 275 & 18 & 18 \\
\hline Observations & 2382 & 2382 & 2382 & 2382 \\
\hline Adjusted R-squared & 0.41 & 0.41 & 0.33 & 0.33 \\
\hline
\end{tabular}

Note: Standard errors in parenthesis. $* * *$ significant at $99 \%$; ** significant at $95 \%$; $*$ significant at $90 \%$. Concentration is the log of the sector's employment share in the region, Diversity is the log of the HirschmanHerfindhal index, Competition is the log of the Hirschman-Herfindhal index of competition, Wages are the $\log$ of total labor costs per month per employee in the region-sector (Euros) and Employment the log of the total local employment in the region. Sector dummies are included at a 3-digit ISIC sector level. 
Table 5: Dynamic Externalities and Long-Run Employment

Growth for Manufacturing

\begin{tabular}{|c|c|c|c|c|}
\hline \multicolumn{5}{|c|}{ Dependent Variable: Employment growth 1985 - 1994 in the "concelho"-sector } \\
\hline Specification & (1) & (2) & (3) & (4) \\
\hline \multirow[t]{2}{*}{ Concentration } & -0.2252 & & & -0.2367 \\
\hline & {$[0.014217]^{* * *}$} & & & {$[0.014784]^{* * *}$} \\
\hline \multirow[t]{2}{*}{ Diversity } & & -0.1114 & & -0.0152 \\
\hline & & {$[0.037379]^{* * *}$} & & [0.035246] \\
\hline \multirow[t]{2}{*}{ Competition } & & & 0.0162 & 0.1185 \\
\hline & & & [0.029987] & {$[0.028831]^{* * *}$} \\
\hline \multirow[t]{2}{*}{ Wage } & -0.0934 & -0.5869 & -0.6017 & -0.0695 \\
\hline & [0.074681] & {$[0.069300]^{* * *}$} & {$[0.069557] * * *$} & [0.074809] \\
\hline \multirow[t]{2}{*}{ Employment } & -0.1692 & -0.0457 & -0.0609 & -0.1706 \\
\hline & {$[0.015427]^{* * *}$} & {$[0.015352]^{* * *}$} & {$[0.014594]^{* * *}$} & {$[0.016589]^{* * *}$} \\
\hline Region Controls & $\mathrm{N}$ & $\mathrm{N}$ & $\mathrm{N}$ & $\mathrm{N}$ \\
\hline Observations & 2,465 & 2,463 & 2,462 & 2,465 \\
\hline Adjusted R-squared & 0.25 & 0.16 & 0.16 & 0.24 \\
\hline
\end{tabular}

Notes: Standard errors in parenthesis. $* * *$ significant at $99 \%$; $* *$ significant at $95 \%$; $*$ significant at $90 \%$. Concentration is the log of the sector's employment share in the region, Diversity is the log of the HirschmanHerfindhal index, Competition is the log of the Hirschman-Herfindhal index of competition, Wages are the log of total labor costs per month per employee in the region-sector (Euros) and Employment the log of the total local employment in the region. Sector dummies are included at a 3-digit ISIC sector level. 
Table 6: Dynamic Externalities and the Long Run Employment Growth, by two-digit ISIC sectors

\begin{tabular}{|c|c|c|c|c|c|c|c|c|}
\hline \multicolumn{9}{|c|}{ Dependent Variable: Employment growth 1985 - 1994 in the "concelho"-sector } \\
\hline Sector & $\begin{array}{c}\text { Food, Beverages } \\
\text { and Tabacco }\end{array}$ & $\begin{array}{c}\text { Textiles } \\
\text { and Clothing }\end{array}$ & $\begin{array}{c}\text { Wood } \\
\text { and Pulp }\end{array}$ & $\begin{array}{c}\text { Paper } \\
\text { and Publishing }\end{array}$ & Chemicals & $\begin{array}{l}\text { Non-Metallic } \\
\text { Mineral Prod. }\end{array}$ & $\begin{array}{r}\text { Basic Metals } \\
\text { (Steal, Iron) }\end{array}$ & Equipment \\
\hline \multirow[t]{2}{*}{ Concentration } & -0.183 & -0.244 & -0.276 & -0.192 & -0.257 & -0.190 & -0.250 & -0.353 \\
\hline & {$[0.0347]^{* * *}$} & {$[0.0497]^{* * *}$} & {$[0.0388] * * *$} & {$[0.0467]^{* * *}$} & {$[0.0490]^{* * *}$} & {$[0.0419]^{* * *}$} & {$[0.1201] * *$} & {$[0.0347]^{* * *}$} \\
\hline \multirow[t]{2}{*}{ Diversity } & -0.025 & -0.136 & 0.069 & 0.049 & -0.295 & 0.112 & 0.470 & 0.107 \\
\hline & {$[0.0717]$} & [0.1091] & {$[0.0805]$} & {$[0.0938]$} & {$[0.1254]^{* *}$} & [0.1129] & {$[0.2828]$} & {$[0.0963]$} \\
\hline \multirow[t]{2}{*}{ Competition } & 0.106 & 0.269 & 0.077 & -0.034 & 0.065 & 0.273 & 0.196 & 0.050 \\
\hline & {$[0.1354]$} & {$[0.1090]^{* *}$} & {$[0.0640]$} & [0.1467] & {$[0.1106]$} & {$[0.1165]^{* *}$} & {$[0.3369]$} & {$[0.0887]$} \\
\hline \multirow[t]{2}{*}{ Wage } & 0.208 & -0.571 & -0.466 & -0.092 & -0.098 & -0.329 & -0.315 & -0.219 \\
\hline & {$[0.1724]$} & {$[0.2575]^{* *}$} & {$[0.1933] * *$} & {$[0.2031]$} & [0.2039] & {$[0.1866]^{*}$} & {$[0.7407]$} & {$[0.1706]$} \\
\hline \multirow[t]{2}{*}{ Employment } & -0.232 & -0.187 & -0.154 & -0.083 & -0.213 & -0.155 & -0.050 & -0.104 \\
\hline & {$[0.0336]^{* * *}$} & {$[0.0546]^{* * *}$} & {$[0.0347]^{* * *}$} & {$[0.0379]^{* *}$} & {$[0.0673]^{* * *}$} & {$[0.0489]^{* * *}$} & {$[0.1551]$} & {$[0.0333]^{* *}$} \\
\hline Observations & 410 & 303 & 372 & 203 & 274 & 285 & 69 & 504 \\
\hline Adjusted R-squared & 0.21 & 0.41 & 0.26 & 0.37 & 0.35 & 0.25 & 0.43 & 0.34 \\
\hline
\end{tabular}

Note : Standard errors in parenthesis. *** significant at $99 \%$; ** significant at $95 \%$; significant at $90 \%$. Concentration is the log of the sector's employment share in the region, Diversity is the log of the Hirschman-Herfindhal index, Competition is the log of the Hirschman-Herfindhal index of competition, Wages are the log of total labor costs per month per employee in the region-sector (Euros) and Employment the log of the total local employment in the region. Sector dummies are included at a 3-digit ISIC sector level. 
Figure 1 - Comon Labor Supply and

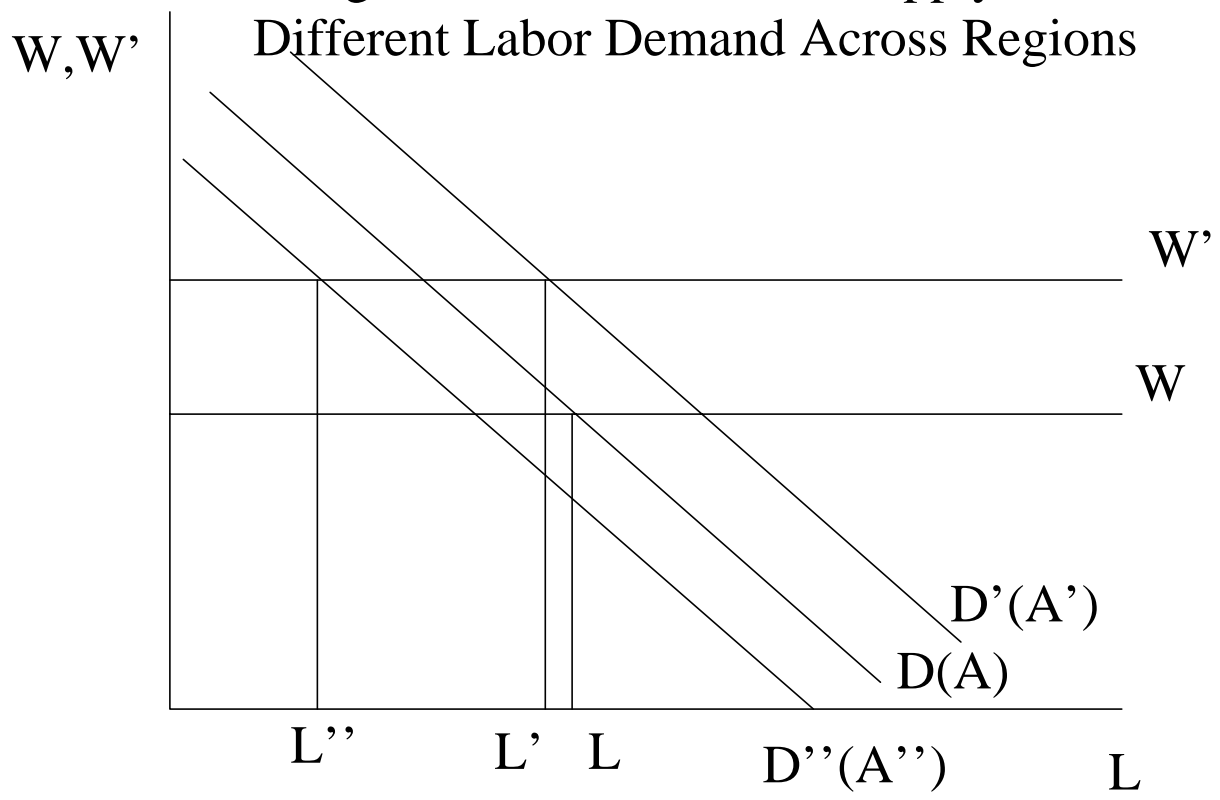

$$
\text { A'"-A<A'-A, L''-L<L'-L }
$$

Figure 2a - Different Labor Supply and

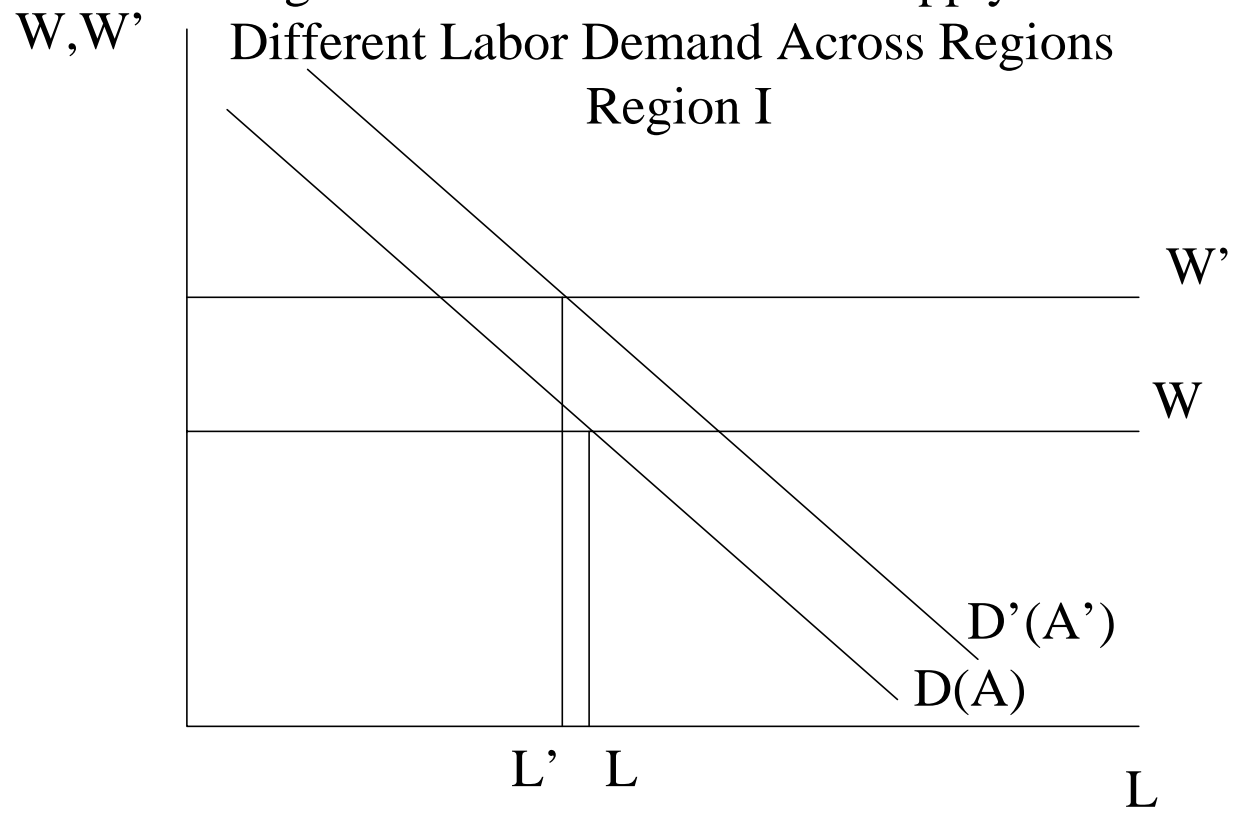

A'>A (positive productivity growth), but L' $<$ L (negative employment growth) 


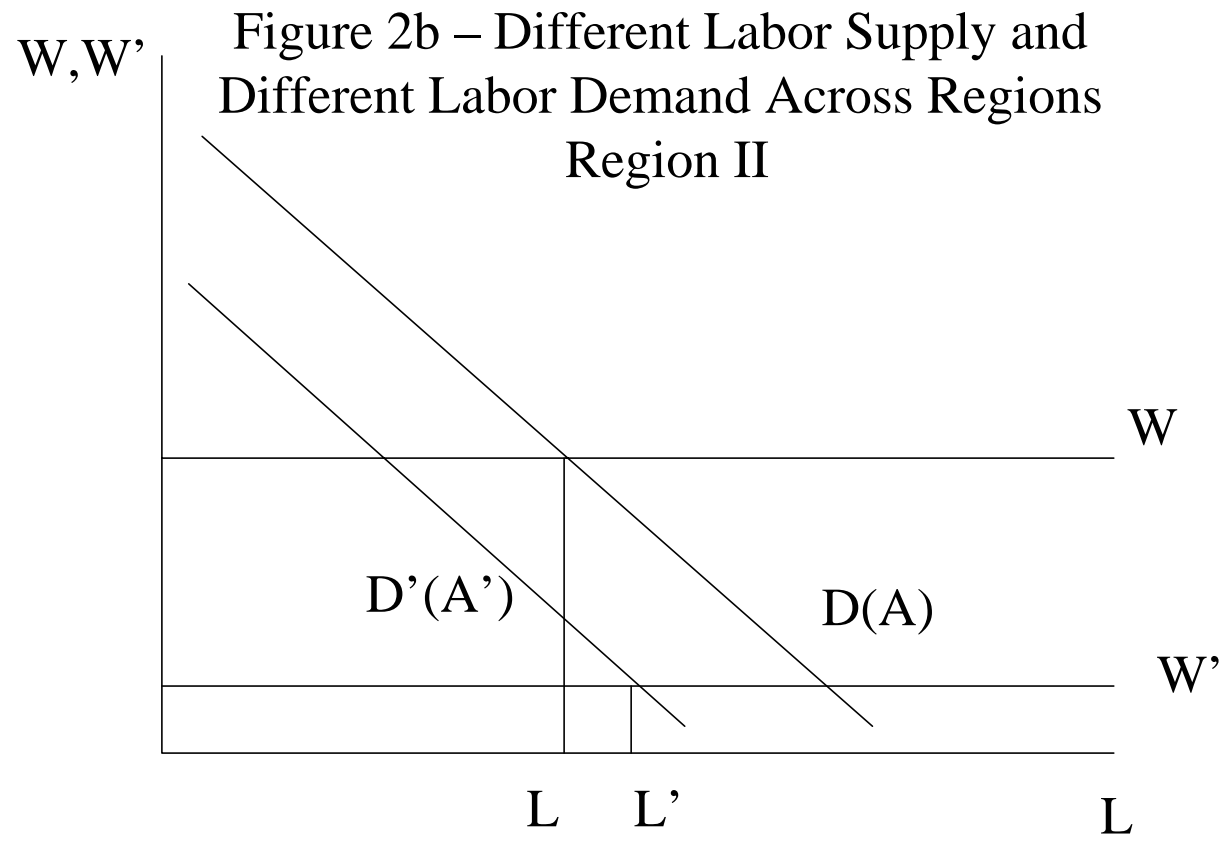

$\mathrm{A}^{\prime}<\mathrm{A}$ (negative productivity growth), but L'>L (positive employment growth)

Figure 2c - Different Labor Supply and

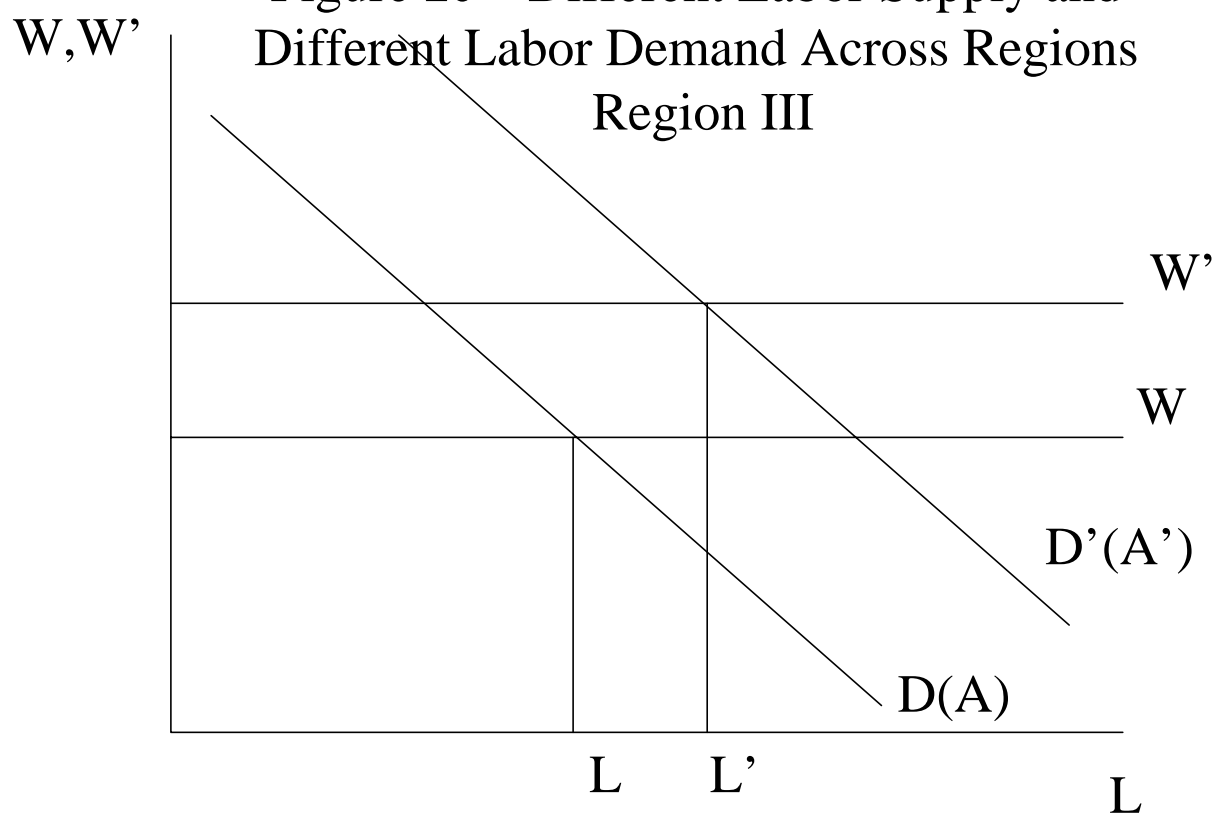

A'>A (positive productivity growth), but L'>L (positive employment growth) 
Figure 3: Cycle and unemployment

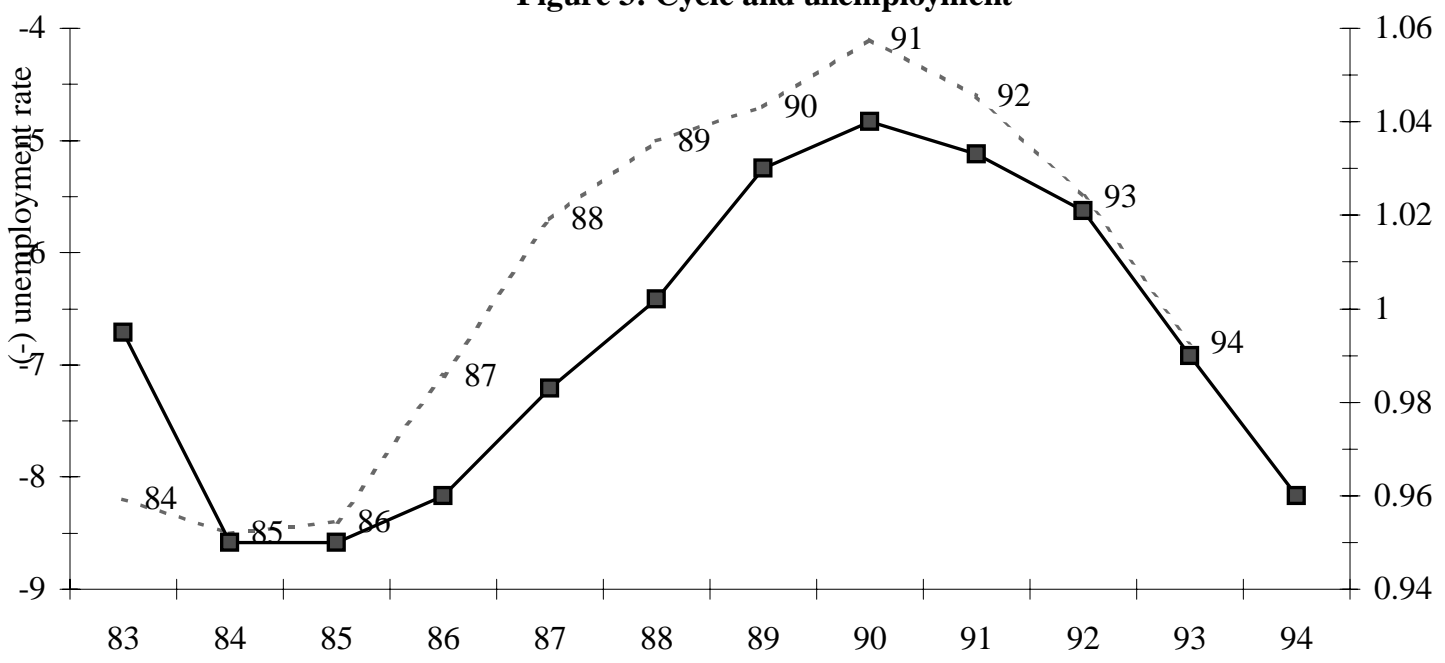

Figure 4: Share of Agriculture, Industry and Services in Total employment
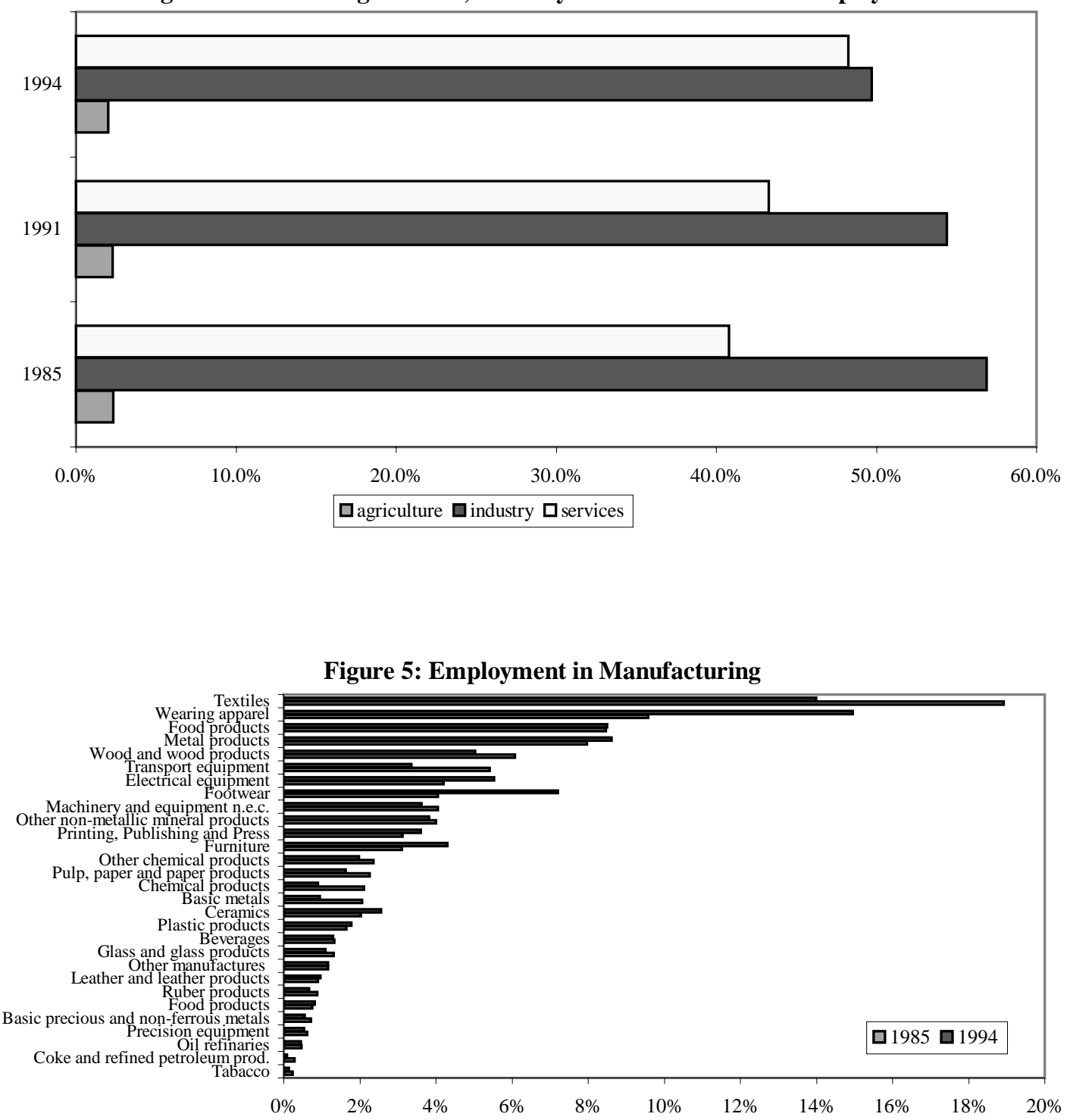